\title{
Nimodipine Increases CSF Somatostatin in Affectively Ill Patients
}

Peggy J. Pazzaglia, M.D., Mark S. George, M.D., Robert M. Post, M.D., David R. Rubinow, M.D., and Candace L. Davis

Preliminary evidence suggests that nimodipine, an L-type calcium channel blocker, is effective in treating some patients with rapidly cycling affective disorders and some phases of Alzheimer's disease, i.e., two syndromes associated with transient or permanent reductions in cerebrospinal fluid (CSF) somatostatin, respectively. CSF somatostatin (SRIF) was measured in 14 affectively ill patients while they were medication-free and during chronic nimodipine treatment. CSF somatostatin significantly increased in patients during active nimodipine treatment compared with ones in the medication-free state. The current findings raise the possibility that nimodipine-induced increases in CSF somatostatin could potentially contribute to its spectrum of efficacy on neuropsychiatric disorders associated with cognitive or affective impairment. Further clinical and preclinical studies are indicated to elucidate the potential mechanisms involved in the elevation of CSF SRIF, whether it is reflected in regional changes in brain, and its possible relevance to nimodipine's clinical actions. [Neuropsychopharmacology 13:75-83, 1995]
KEY WORDS: Somatostatin; Calcium channel blocker; Dihydropyridine; Nimodipine

Somatostatin (somatotropin release-inhibiting factor; SRIF) is a neuropeptide widely distributed in the body and primarily concentrated in the central and peripheral nervous system. In addition to its role as an inhibitor to growth hormone release, other regulatory functions have been attributed to it, including neurotransmission, glandular secretion, smooth muscle contractility, and cell proliferation. Alterations in cerebrospinal fluid (CSF) SRIF have been associated with a variety of neurological and neuropsychiatric disorders (Patel et al. 1977, Rubinow et al. 1995). Specifically, increased levels of SRIF have been found in some inflammatory or

Fellows supported by the Stanley Foundation (PJP, MSG); from the Biological Psychiatry Branch, Section of Psychobiology (RMP, CLD), and Section of Behavioral Endocrinology (DRR), of the National Institute of Mental Health, Bethesda, MD.

Address correspondence and reprint requests to: Robert M. Post, Chief, Biological Psychiatry Branch, NIMH, Bldg. 10, Room 3N212, 10 Center Drive MSC 1272, Bethesda, MD 20892-1272

Received July 26, 1994; revised January 11, 1995; accepted January 27, 1995. destructive neurological diseases such as cerebral tumor, meningitis, spinal cord disease, nerve root compression, and metabolic encephalopathy (Beal et al. 1985; Patel 1992). The elevation of CSF SRIF in these disorders has been attributed to possible "leakage" from damaged or anoxic neurons.

In contrast, decreased levels of CSF SRIF have been associated with neuropsychiatric disorders thought due to either a "functional" neuronal alteration or cell loss. Decreased CSF SRIF has been shown to occur in Parkinson's disease (Dupont et al. 1982), Huntington's chorea (Cramer et al. 1981), delirium (Koponen et al. 1989), Alzheimer's disease (Wood et al. 1982; Francis et al. 1984; Serby et al. 1984; Soninen et al. 1984, 1988; Cramer et al. 1985; Beal et al. 1986; Gomez et al. 1986; Sunderland et al. 1987; Davis et al. 1988), active multiple sclerosis (Sorenson et al. 1980, 1987; Beal et al. 1985; Su et al. 1990), ACTH-dependent Cushings disease (Kling et al. 1986), and depression (Rubinow et al. 1983; Lundqvist 1984; Black et al. 1986; Sunderland et al. 1987; Davis et al. 1988; Molchan et al. 1991; Bissette and Meyers 1992). The decrements of CSF SRIF are staterelated in multiple sclerosis and in depression (i.e., they 
improve with recovery from the active episode), but are permanent in patients with Alzheimer's disease (Rubinow and Post 1994). Administration of cysteamine (a depletor of somatostatin) to animals results in impaired performance on both learning and memory tasks (Vecsel et al. 1983; Walsh et al. 1985) and can be reversed by intracerebroventricular somatostatin (Vecsel et al. 1984), further suggesting a possible role for this peptide in the memory deficits associated with many of the neuropsychiatric disorders noted earlier.

Studies have shown that SRIF exerts potent electrophysiological actions on neurons in several brain regions (Renaud et al. 1975; Randic and Miletic 1978; Olpe et al. 1980; Philis and Kirkpatric 1980; Delfs and Dichter 1983), including the hippocampus (Dodd and Kelly 1978; Scharfman and Schwartzkroin 1988,1989). All major regions of the mammalian hippocampus contain SRIF-containing interneurons and receptors (Epelbaum 1986). Furthermore, somatostatin has been shown to exert both excitatory and inhibitory actions on hippocampal neurons (Renaud et al. 1975). Several mechanisms have been implicated in SRIF's ability to decrease the responsiveness of target cells on a cellular level. These include SRIF's ability to bind $G_{i}$ (thus inhibiting adenylate cyclase), lower cellular cyclic adenosine monophosphate (cAMP) levels, activate potassium channels with subsequent hyperpolarization, and reduce calcium spiking thought due to either reduced gating of voltage-dependent channels secondary to membrane hyperpolarization or direct effects on calcium channels (Epelbaum 1986; Login and Judd 1986; Wollheim et al. 1990). Most recently a direct effect of somatostatin on gene transcription at the AP- 1 binding site on DNA has been reported (Todisco et al. 1994).

The apparent association between kindled seizures and elevation in SRIF, as well as SRIF depletion and anticonvulsant effects, suggests that SRIF may possess pro-convulsant properties and play a role in seizure development in some animal models (Higuchi et al. 1983; Higuchi et al. 1984; Katakami et al. 1985; Kato et al. 1986; Perlin et al. 1987; Pitkanen et al. 1987; Marksteiner and Sperk 1988; Nadi 1988; Pitkanen et al. 1988; Olenik et al. 1989; Shinoda et al. 1989,1991; Sperk et al. 1992). Intracerebral administration of somatostatin in rats has been reported to precipitate atypical seizures (Katakami et al. 1985), whereas administration of either cysteamine or somatostatin antiserum appears to inhibit kindled seizures (Higuchi et al. 1983). However, SRIF has been shown potentially to possess anticonvulsant properties in some animal models (Rothman 1984; Tartara et al. 1984).

Nimodipine, the 1,4 dihydropyridine L-type calcium channel blocker, has been shown to have a preferential effect on the cerebrovascular system in animal models (Hoffmeister et al. 1982; Langley and Sorkin 1989; Marin 1988; Physician's Desk Reference 1990). In addition, its lipid solubility and potential selective central vascular effects are thought related to its utility in treating cerebral vasospasm. In both animal and clinical studies, its use in subarachnoid hemorrhage and acute ischemic attacks appears associated with improvement in neurological outcome (Hoffmeister et al. 1982; Martinez-Vila et al. 1990; Physician's Desk Reference 1990). Moreover, nimodipine has anticonvulsant effects in some animal models of epilepsy, including those that are electrically induced or the result of ethanol withdrawal, high atmospheric pressure, pentylenetetrazol, and kindling (Dolin et al. 1986, 1988; Meyer et al. 1986, 1987; Vezzani et al. 1988; Paczynsky et al. 1990; Wurpel and Iyer 1994). Additionally, there have been a few preliminary clinical observations supporting its anticonvulsant effects in humans (Brandt et al. 1988; Larkin et al. 1991; de Falco et al. 1992).

Nimodipine possesses significant cerebrovascular effects and is currently FDA approved for the treatment of subarachnoid hemorrhage (Physician's Desk Reference 1990). In addition to its effects on cerebrovascular vasospasm, nimodipine may possibly possess clinically relevant effects on cognition (Gispen et al. 1988; Ulrich and Stieglitz 1988; Izquierdo 1990) and seizures (Dolin et al. 1986, 1988; Meyer et al. 1986; Vezzani et al. 1988; Paczynsky et al. 1990; Larkin et al. 1991; de Falco et al. 1992), and may provide acute or prophylactic treatment of recurrent mood disorders (Montenegro et al. 1985; Brunet et al. 1990; Manna 1991; Pazzaglia et al. 1993; McDermut et al. 1995). Whether nimodipine's profile of efficacy turns out to be clinically different from that of traditional calcium channel blockers (Dubovsky 1993) remains to be delineated. In light of nimodipine's suggestive and somatostatin's putative effects on cognition, seizures, and mood, we examined the effects of chronic nimodipine treatment on SRIF CSF. The present study reports a significant increase in CSF SRIF levels in patients with affective illness treated with chronic oral nimodipine and discusses the implications of these findings.

\section{METHODS}

Fourteen patients with primary affective illness as determined by Research Diagnostic Criteria (RDC), SADSLA, and DSM-III-R criteria were admitted as inpatients to the 3-West Clinical Research Unit of the Biological Psychiatry Branch of the National Institute of Mental Health. Patients were excluded from the study if, based on history and laboratory assessment, they had other neurological illness or were substance abusers. All patients were medically healthy except for their refractory affective disorder (Table 1).

Four patients had recurrent unipolar depression and 10 had bipolar disorder. Two of the unipolar depressed patients also met criteria for recurrent brief depression (Angst et al. 1990; Montgomery et al. 1990). 
Table 1. Patient Demographics and Treatment Variables

\begin{tabular}{|c|c|c|c|c|c|c|c|c|c|}
\hline \multirow{2}{*}{$\begin{array}{l}\text { Patient } \\
\text { No. }\end{array}$} & \multirow{2}{*}{$\begin{array}{c}\text { Age }(y r) / \\
\text { Gender }\end{array}$} & \multirow{2}{*}{$\begin{array}{c}\text { Age at } \\
\text { Onset } \\
(y r)\end{array}$} & \multirow[b]{2}{*}{ Dx } & \multirow{2}{*}{$\begin{array}{c}\text { No. of } \\
\text { Admissions }^{a}\end{array}$} & \multirow{2}{*}{$\begin{array}{c}\text { Length of } \\
\text { Illness }(y r)^{a}\end{array}$} & \multirow{2}{*}{$\begin{array}{c}\text { Dose } \\
(m g / d)\end{array}$} & \multirow{2}{*}{$\begin{array}{c}\text { Days } \\
\mathbf{R x}\end{array}$} & \multicolumn{2}{|c|}{ Depression $^{b}$} \\
\hline & & & & & & & & Pre Rx & Post $\mathbf{R x}$ \\
\hline 1 & $24 / \mathrm{M}$ & 14 & BP2 & 5 & 10 & 720 & 98 & 5 & 7 \\
\hline 2 & $55 / \mathrm{M}$ & 49 & $\begin{array}{l}\text { BP2 } \\
\text { RC }\end{array}$ & 0 & 6 & 360 & 37 & 1 & 7 \\
\hline 3 & $32 / F$ & 12 & UPD & 1 & 20 & 420 & 21 & 5 & 6 \\
\hline 4 & $43 / F$ & 7 & $\mathrm{BP} 2$ & 0 & 36 & 180 & 26 & 7 & 7 \\
\hline 5 & $28 / F$ & 18 & $\begin{array}{l}\text { UPD } \\
\text { RBD }\end{array}$ & 0 & 14 & 270 & 83 & 1 & 1 \\
\hline 6 & $28 / F$ & 21 & $\begin{array}{l}\text { BP2 } \\
\text { URC }\end{array}$ & 2 & 19 & 600 & 95 & 1 & 3 \\
\hline 7 & $42 / \mathrm{M}$ & 34 & $\begin{array}{l}\text { BP2 } \\
\text { URC }\end{array}$ & 4 & 8 & 420 & 90 & 3 & 5 \\
\hline 8 & $53 / \mathrm{M}$ & 25 & UPD & 2 & 28 & 480 & 96 & 8 & 8 \\
\hline 9 & $27 / \mathrm{M}$ & 9 & $\begin{array}{l}\text { UPD } \\
\text { RBD }\end{array}$ & 1 & 18 & 480 & 64 & 8 & 4 \\
\hline 10 & $52 / \mathrm{F}$ & 7 & UPD & 0 & 45 & 240 & 38 & 8 & 8 \\
\hline 11 & $35 / F$ & 15 & $\mathrm{BP} 2$ & 6 & 20 & 360 & 51 & 9 & 8 \\
\hline 12 & $48 / F$ & 14 & $\begin{array}{c}\text { BP1 } \\
\text { UURC }\end{array}$ & 2 & 34 & 480 & 92 & 1 & 1 \\
\hline 13 & $23 / \mathrm{M}$ & 17 & BP1 & 6 & 6 & 720 & 61 & 5 & 6 \\
\hline 14 & $40 / F$ & 34 & $\begin{array}{c}\text { BP2 } \\
\text { URC }\end{array}$ & 3 & 6 & 360 & 69 & 9 & 1 \\
\hline
\end{tabular}

Abbreviations: BP1 = bipolar type I; BP2 = bipolar type II; RBD = recurrent brief depression; $\mathrm{RC}=$ rapid cycling; UPD = unipolar depression; URC = ultra-rapid cycling; UURC = ultradian or ultra-ultra-rapid cycling.

a Prior to admission to NIMH.

${ }^{b}$ Bunney-Hamburg rating scale on the day of the LP.

All of the bipolar patients were rapid cyclers (greater than 4 episodes per year), and nine had bipolar type II disorder. On the day of the lumbar puncture during placebo phase of the study, all but three patients were depressed (only patients 2,5 , and 6 were in a relatively euthymic state at baseline). On the day of the lumbar puncture on nimodipine, eight patients remained depressed, i.e., they experienced a depression rating of greater than or equal to 6.5 when the mania scale is less than 1 on the Bunney-Hamburg, while six patients were euthymic (as observed in patients $4,5,6$, $7,9,12)$.

Written informed consent was obtained for periods of medication-free evaluation and for treatment with nimodipine under double-blind, placebo-controlled conditions as described in detail elsewhere (Pazzaglia et al. 1993). Each patient underwent a complete physical and neurological exam. Laboratory assessments included the following: baseline electrocardiogram; urine pregnancy tests for women of childbearing age; magnetic resonance imaging of the brain; electroencephalography; blood specimens for complete blood count, thyroid functions, and a blood chemistry panel including electrolytes and liver function tests. Blind ratings were completed twice daily by a consensus of trained nursing staff using the 15-point Bunney-Hamburg rating scales for depression, mania, anger, psychosis, and anxiety as previously described (Bunney and Hamburg 1963).

Following subjective reports of memory improve- ment even in some of the nimodipine nonresponders (Pazzaglia et al. 1993), the Buschke selective reminding task (Lezak 1983) was introduced and used before and during nimodipine treatment in seven patients. In selective reminding, the patient was requested to recall as many words as possible in any order from a list of 12 words just read. Following each trial the examiner repeated the words the patient omitted in that trial. The reminding and recall trials continued until the patient was able to recite the entire list. Measures of storage and retrieval were defined as the following: "long-term storage" was the number of words recalled in each trial; "total long-term storage" was the sum of words in storage across trials; "consistent long-term retrieval" from storage consisted of the number of words recalled in any given trial that were recalled on all subsequent trials without reminding; and "total consistent long-term retrieval" was a sum of the total and consistent (Lezak 1983). Other memory tasks included in these preliminary evaluations were the digit span, digit symbol substitution, Benton visual memory, and word generation tasks.

Lumbar punctures (LP) were performed on all patients at approximately 9:00 A.M., while they were in a fasting state after 9 hours of overnight bed rest, and were performed in the lateral decubitus position. Each subject was prepared and draped in a sterile manner prior to the insertion of a 20 -gauge needle, usually placed in the L4-5 vertebral interspace. Approximately $32 \mathrm{cc}$ of CSF was collected under normal pressure. An 
aliquot for the measurement of CSF somatostatin from the 21st-22nd cc was collected in $100 \mu \mathrm{l} 1 \mathrm{~N}$ acetic acid as a preservative and was immediately placed on dry ice and then stored at $-70^{\circ} \mathrm{C}$ until the time of assay.

CSF was obtained from each patient during both the placebo and active nimodipine phases of this study. Following a placebo (B) period, patients were treated with active oral nimodipine monotherapy (A) (Nimotrop ${ }^{\circledR}$, Miles Laboratories, West Haven, CT) in a B-A-B design, and in some instances responders were rechallenged with nimodipine (B-A-B-A) (Pazzaglia et al. 1993; McDermutt et al. 1995). Medication-free LPs were obtained after at least 2 weeks on placebo. The active drug phase was instituted with blind nimodipine at $90 \mathrm{mg} / \mathrm{d}$ given in 3 divided doses, which was then titrated up to the maximum tolerated dose for each patient. The initial upper dose limit for nimodipine allowed by the FDA was $360 \mathrm{mg} / \mathrm{d}$; this was then increased to a maximum of $720 \mathrm{mg} / \mathrm{d}$ as tolerated.

CSF SRIF levels were determined using a modification of the radioimmunoassay described by Patel and Reichlin (1979). The assay used delayed addition of a Sep-Pak C-18 purified label ([225I]-Tyr1-SRIF) (Millipore, Milford, MA), synthetic cyclic somatostatin standards, rabbit antisomatostatin antibody (Incstar, Stillwater, MN), and charcoal separation. The assay measured somatostatin and its $\mathrm{N}$-terminal extension precursors (Patel and Reichlin 1979). The sensitivity of this assay was $1.25 \mathrm{pg} / \mathrm{ml}$. For the control at $53.7 \mathrm{pg} / \mathrm{ml}$, the interassay coefficient of variation was $8.8 \%$. The mean ED20, ED50, and ED80 were $18.1 \mathrm{pg} / \mathrm{ml}, 51.7$ $\mathrm{pg} / \mathrm{ml}$, and $148 \mathrm{pg} / \mathrm{ml}$, respectively. Specimens were assayed in two batches, with each patient's paired placebo and nimodipine value run in the same assay. The first eight patients' specimens were assayed in the first assay and then reassayed in the second, with samples from the remaining six subjects. The mean of both assays provided the most conservative statistical outcome and was thus used for these patients and for the statistical analysis.

A paired Student's T-test was used to compare the change in CSF SRIF between medication-free and active drug phases. In addition, Pearson's correlation was used to measure the potential relationships between change in CSF SRIF, nimodipine dose, change in mood (measured by Bunney-Hamburg depression scale), or change in memory (measured by the Buscke).

\section{RESULTS}

The mean maintenance dose of nimodipine was 427 $\mathrm{mg} / \mathrm{d}$ after a mean duration of 26 days of treatment at the time of the lumbar puncture. Nimodipine treatment was associated with a significant elevation in CSF con- centrations of SRIF (Figure 1). The increases in 11 of the 14 patients were significant using either the mean of the first and second assays or the individual values from each assay.

No significant relationship was found between the change in CSF SRIF and nimodipine dose $(r=0.10$, $p=.75, n=14$ ). Additionally, no significant correlation was found between change in CSF SRIF and change in mood ratings on the day of the LP, as measured by the Bunney-Hamburg depression scale ( $r=$ $0.05, p<0.45, n=14$ ).

Preliminary analysis of the relationship between change of somatostatin and memory assessments showed a positive correlation between measures for long-term memory storage on the Buschke $(r=0.83$, $p<0.02, n=7$, trial $1 ; r=0.85, p<0.01, n=7$, trial 2 ) and measures of consistent long-term retrieval ( $r=$ $0.89, p<0.01, n=7)$. No relationship was found between change in somatostatin and other measures of memory, including digit span, symbol digit, Benton visual memory, and word generation.

\section{DISCUSSION}

Chronic treatment with the calcium channel blocker nimodipine was associated with significant increases

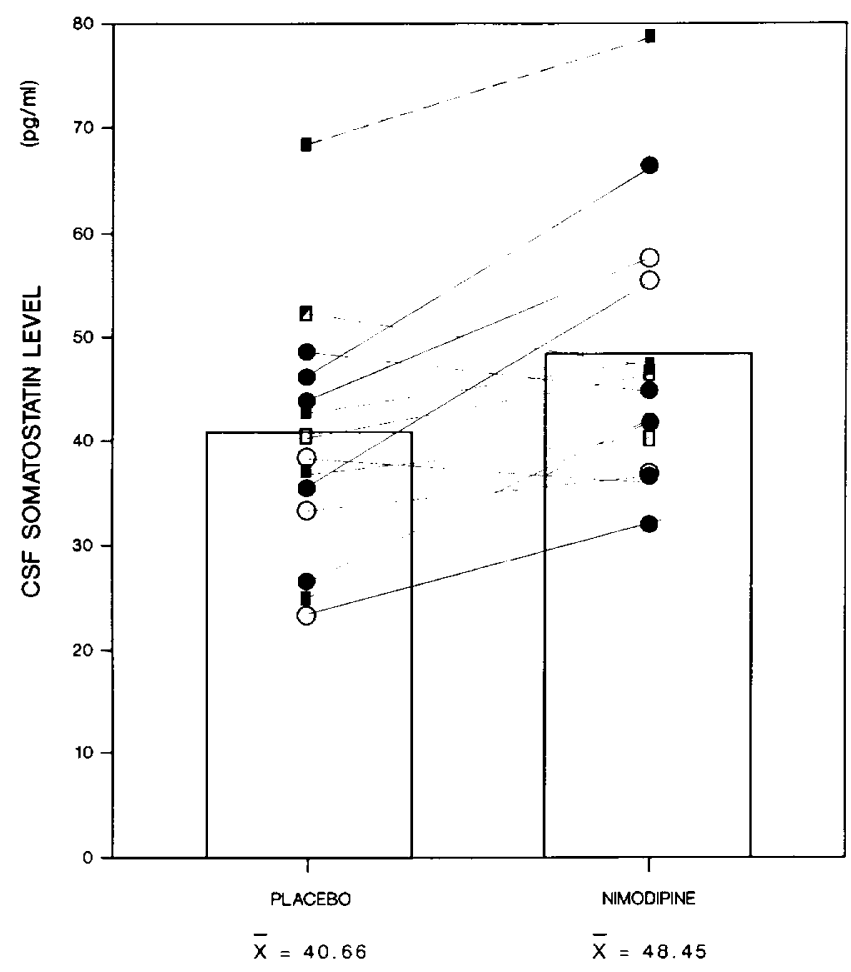

Figure 1. Nimodipine increases somatostatin in CSF of affectively ill patients. ( female depressed, o female euthymic, - male depressed, $\square$ male euthymic; $t=3.48, p<.004$ ). 
in CSF concentrations of SRIF in patients being treated for refractory mood disorders. The increase in CSF SRIF occurred in a heterogenous group of affectively ill patients, and it was not related to initial mood state or nimodipine dose. The increase in CSF SRIF was positively correlated with the degree of improvement on one test of memory function in a preliminary analysis of the first seven subjects tested.

Alterations in brain and CSF SRIF levels characterize several neuropsychiatric disorders. Low SRIF in Alzheimer's disease reflects an apparently permanent decrease in neural SRIF, and in some studies this decrease is proportional to the degree of cognitive decline (Francis et al. 1987). Attempts to treat Alzheimer's disease with intravenous SRIF analogues have been unsuccessful, presumably due to the inability of SRIF to cross the blood-brain barrier (Cutler et al. 1985). As reviewed by Post et al. (1988) and Rubinow et al. (1995), a transient illness-related decrease in CSF SRIF has been a consistent finding in patients with depression as compared to normal volunteers or other control subjects (Gerner and Yamada 1982; Rubinow et al. 1983; Agren and Lundqvist 1984; Rubinow 1986; Black et al. 1986; Bissette and Meyers 1992).

In this study, the increases in SRIF observed during nimodipine treatment occurred independent of the level of initial depression or the degree of clinical improvement, further suggesting that they represent a pharmacological effect of the drug. Larger studies in more homogenous populations of depressed patients are required to provide evidence of a relationship between the increase in CSF SRIF and improvement in affect, cognition, endocrine, and other functions putatively linked to SRIF in the literature.

Nimodipine is primarily utilized clinically for treating cerebrovascular disease such as subarachnoid hemorrhage Kazda et al. 1979; Hoffmeister et al. 1982; Allen et al. 1983; Marin 1988; Lewis et al. 1988; Mee et al. 1988), acute ischemic attacks (Pickard et al. 1989), and migraines (Gelmers 1983; Peroutka 1983; Solomon 1985; Jonsdottir et al. 1987). More recently, animal studies also suggest that nimodipine may have utility in treating epilepsy (Dolin et al. 1986, 1988; Meyer et al. 1986, 1987; Vezzani et al. 1988; Paczynsky et al. 1990), cognitive decline (Gispen et al. 1988; Ulrich and Stieglitz 1988; Izquierdo 1990), and mood disorders, as shown by positive effects in the Porsolt swim test and learned helplessness models of depression (de Jonge et al. 1993). These preclinical data are convergent with recent preliminary clinical studies suggesting positive effects of nimodipine in patients with epilepsy (Brandt et al. 1988; Larkin et al. 1991; de Falco et al. 1992), Alzheimer's disease (Tollefson 1990; Dubovsky 1993), and mood disorders (Brunet et al. 1990; Manna 1991; Pazzaglia et al. 1993; McDermut et al. 1995).
The nimodipine-induced increases in CSF SRIF are in contrast to the decreases in CSF SRIF associated with fluphenazine (Doran et al. 1989) and carbamazepine (Steardo et al. 1986; Rubinow et al. 1992). In five patients with low baseline CSF SRIF, zimelidine increased CSF SRIF, although it is unclear whether this is a direct pharmacological effect or related to improvement in depression (Rubinow 1986). In the current study, nimodipine increased CSF SRIF independent of both the initial SRF values (which are low compared to controls) and the degree of clinical improvement noted. Whether nimodipine would increase CSF SRIF in controls with normal baseline levels and whether this CSF change would be reflected in regional brain alterations remain to be seen. If these were the case, nimodipine's ability to increase somatostatin could play a role in some of its therapeutic actions. There are few pharmacologic probes that increase SRIF, so further investigation of the effect of nimodipine in disorders characterized by low SRIF might be fruitful. Because depletion of SRIF results in impaired learning (Vecsel et al. 1984), and administration of SRIF into the brain facilitates learning and memory (e.g., delays extinction of learned avoidance response and reverses electric shock-induced amnesia) (Walsh et al. 1985), one could ask whether nimodipine's putative effects in Alzheimer's disease (Tollefson 1990; Dubovsky 1993) are related to its increase in CSF SRIF or to some other direct or indirect consequence of calcium channel blockade.

Somatostatin has been shown to block the spontaneous oscillations in intracellular calcium of pituitary somatotrophs by inhibiting the generation of action potentials of the cells (Wollheim et al. 1990). SRIF's interference with intracellular calcium spiking has been explained by either reduction in gating of voltagedependent calcium channels secondary to direct effects on calcium channels or potassium channel-related membrane hyperpolarization (Lewis et al. 1986). Thus, the observed increases in SRIF could interact with nimodipine's direct effect on L-type channels to alter cellular calcium dynamics. The specificity of nimodipine's ability to increase CSF SRIF and the way this increase might relate to nimodipine's profile of clinical efficacy remain to be examined by future preclinical and clinical studies.

\section{REFERENCES}

Agren H, Lundqvist G (1984): Low levels of somatostatin in human CSF mark depressive episodes. Psychoneuroendocrinology 9:233-248

Allen GS, Ahn HS Prezoist TJ, Battye R, Boone SC, Chou SN, Kelly DL, Weir BK, Crabbe RA, Labik PJ, Rosenbloom SB, Dorsey FC, Ingram CR, Mellitis DE, Bertsch LA, Boisvert D, Hundley MB, Johnson RD, Strom JOA, 
Transou CR (1983): Cerebral arterial spasm: A controlled trial of nimodipine in patients with subarachnoid hemorrhage. New Engl J Med 308:619-624

Angst J, Merikangas K, Scheidegger P, Wicki W (1990): Recurrent brief depression: A new subtype of affective disorder. J Affective Disord 19:87-89

Beal MF, Mazurek MF, Black PMcL, Martin JB (1985): Human cerebrospinal fluid somatostatin in neurological disease. J Neurol Sci 71:91-104

Beal MF, Growdon JH, Mazurek MF, Martin JB (1986): CSF somatostatin-like immunoreactivity in dementia. Neurology 36:294-297

Bissette G, Meyers B (1992): Minireview somatostatin in Alzheimer's disease and depression. Life Sci 51:1389-1410

Black PM, Ballatine HT, Carr DB, Beal MF, Martin JB (1986): Beta-endorphin and somatostatin concentrations in ventricular cerebrospinal fluid of patients with affective disorder. Biol Psychiatry 21:1077-1081

Brandt I, Saveland H, Ljunggren B, Andersson KE (1988): Control of epilepsia partialis continuans with intravenous nimodipine: Report of two cases. J Neurosurg 69:949-950

Brunet G, Cerlich B, Robert S, Dumas S, Souetre E, Darcourt G (1990): Open trial of a calcium antagonist nimodipine, in acute mania. Clin Neuropharmacol 13:224-228

Bunney WE, Jr, Hamburg DA (1963): Methods for reliable longitudinal observations in behavior. Am J Psychiatry 9:280-294

Cramer H, Kohler J, Oepen G, Schomburg G, Schroter E (1981): Huntington's chorea: Measurements of somatostatin, substance $P$ and cyclic nucleotides in the cerebrospinal fluid. J Neurol 225:183-187

Cramer H, Schaudt D, Rissler K, Strubel D, Warter JM, Kuntzmann F (1985): Somatostatin-like immunoreactivity and substance-P-like immunoreactivity in the CSF of patients with senile dementia of Alzheimer type, multi-infarct syndrome and communicating hydrocephalus. J Neurol 232:346-351

Culter NR, Haxby JV, Narang PR (1985): Evaluation of an analogue of somatostatin (L363; 586). N Engl J Med 312:725

Davis KL, Davidson M, Yang RK, Davis BM, Siever LJ, Mohs RC, Ryan T, Coccaro E, Bierer L, Targum SD (1988): CSF somatostatin in Alzheimer's disease, depressed patients, and control subjects. Biol Psychiatry 24:710-712

de Falco FA, Bartiromo U, Majello L, Di Geronimo G, Mundo $P$ (1992): Calcium antagonist nimodipine in intractable epilepsy. Epilepsia 33:343-345

de Jonge M, Friedl A, De Vry J (1993): CNS pharmacology of nimodipine: Antidepressant effects, drug discrimination and $\mathrm{Ca}^{2+}$ imaging. Presented as part of the Calcium Antagonists in CNS Investigation Meeting, Sante $\mathrm{Fe}$, New Mexico, April 1-9, 1992

Delfs J, Dichter M (1983): Effects of somatostatin on mammalian cortical neurons in culture: Physiological actions and unusual dose-response characteristics. J Neurosci 3:1176-1187

Dodd J, Kelly J (1978): Is somatostatin an excitatory transmitter in the hippocampus? Nature 273:674-677

Dolin SJ, Grant AJ, Hunter AB, Little HJ (1986): Anticonvulsant profile and whole brain concentrations of nitrendipine and nimodipine. Br J Pharmacol 89:866P
Dolin SJ, Hunter AB, Halsey MJ, Little HJ (1988): Anticonvulsant profile of the dihydropyridine calcium channel antagonists, nitrendipine and nimodipine. Eur J Pharmacol 152:19-27

Doran AR, Rubinow DR, Wolkowitz OM, Roy A, Breier A, Pickar D (1989): Fluphenazine treatment reduces CSF somatostatin in patients with schizophrenia: Correlations with CSF HVA. Biol Psychiatry 25:431-439

Dubovsky SL (1993): Calcium antagonists in manic-depressive illness. Neuropsychobiology 127(3):184-12

Dupont E, Christensen SE, Hansen AAP, Olivarius BD, Orskov H (1982): Low cerebrospinal fluid somatostatin in Parkinson's disease: an irreversible abnormality. Neurology 32:312-314

Epelbaum J (1986): Somatostatin the central nervous system: Physiology and pathological modifications. Prog Neurobiol 27:63-100

Francis PT, Bowen DM, Neary D, Palo J, Wikstrom J, Olney $\mathrm{N}$ (1984): Somatostatin-like immunoreactivity in lumbar cerebrospinal fluid from neurohistochemically examined demented patients. Neurobiol Aging 5:183-186

Francis PT, Bowen DM, Lowe SL, Neary D, Mann DMA, Snowden JS (1987): Somatostatin content and release measured in cerebral biopsies from demented patients. J Neurol Sci 78:1-16

Gelmers HJ (1983): Nimodipine, a new calcium antagonist, in the prophylactic treatment of migraine. Headache 23:106-109

Gerner RH, Yamada T (1982): Altered neuropeptide concentrations in cerebrospinal fluid of psychiatric patients. Brain Res 238:298-302

Gispen WH, Schuurman T, Traber J (1988): Nimodipine and neural plasticity in the peripheral nervous system of adult and aged rats. In Morad M (ed), The Calcium Channel: Structure, Function and Implications. Berlin-Heidelberg, Springer-Verlag, pp 491-502

Gomez DP, Rondot P, Raivre-Bauman A, Valade D, Puymirat J (1986): Somatostatin-like immunoreactivity and acetylcholinesterase activities in cerebrospinal fluid of patients with Alzheimer's disease and senile dementia of the Alzheimer type. Psychoneuroendocrinology 11:69-73

Higuchi T, Sikand GS, Kato N, Wada JA, Frieson HG (1983): Profound suppression of kindled seizures by cysteamine: Possible role of somatostatin in kindled seizures. Brain Res 288:359-362

Higuchi T, Kokubu T, Sikand GS, Wada JA, Friesen HG (1984): A study of somatostatin receptors in amygdaloidkindled rat brain. J Neurochem 43:1271-1276

Hoffmeister F, Benz U, Heise H, Krause P, Neuser V (1982): Behavioral effects of nimodipine in animals. ArzneimForsch 32:347-360

Izquierdo I (1990): Nimodipine and the recovery of memory. Trends Pharmacol Sci 11:309-310

Jonsdottir M, Meyer JS, Rogers RL (1987): Efficacy, side effects and tolerance compared during headache treatment with three different calcium blockers. Headache 27:364-369

Katakami H, Arimura A, Frohman LA (1985): Involvement of hypothalamic somatostatin in the suppression of growth hormone secretion by central corticotropinreleasing factor in conscious male rats. Neuroendocrinology 41:390-393 
Kato M, Kakegawa T, Suzuki M (1986): Electrical stimulation of several limbic areas suppressed the growth hormone (GH) release induced by human pancreatic $\mathrm{GH}$-releasing factor in pentobarbital-anesthetized rats. Endocrinology 118:955-960

Kazda S, Hoffmeister F, Garthoff B, Towart R (1979): Prevention of the postischaemic impaired reperfusion of the brain by nimodipine (BAY e 9736). Acta Neurol Scand 60(suppl 72): 104-105

Kling MA, Rubinow DR, Chrousos GP, Doran AR, Gold PW (1986): CSF somatostatin levels are decreased in patients with ACTH-dependent Cushing's syndrome. In Proc. 41st Annual Meeting of the Society of Biological Psychiatry, abstract 92

Koponen H, Stenback U, Mattila E, Reinikainen K, Soininen H, Riekkinen PJ (1989): Cerebrospinal fluid somatostatin in delirium. Psychol Med 19:605-609

Langley MS, Sorkin EM (1989): Nimodipine: A review of its pharmacodynamic and pharmacokinetic properties, and therapeutic potential in cerebrovascular disease. Drugs 37:669-699

Larkin JG, McKee PJW, Blacklaw J, Thompson GG, Morgan PC, Brodie MJ (1991): Nimodipine in refractory epilepsy: A placebo-controlled, add-on study. Epilepsy Res 9:71-77

Lewis DL, Weight FF, Luini A (1986): A guanine nucleotidebinding protein mediates the inhibition of voltagedependent calcium current by somatostatin in a pituitary cell line. Proc Natl Acad Sci USA 83:9035-9039

Lewis PJ, Weir BKA, Nosko MG, Tanabe T, Grace MG (1988): Intrathecal nimodipine therapy in a primate model of chronic cerebral vasospasm. Neurosurgery 22:492-499

Lezak MD (1983): In Neurospsychological Assessment. 2nd ed. New York, Oxford University Press, pp 473-474

Login ES, Judd AM (1986): Trophic effects of somatostatin on calcium flux: Dynamic analysis and correlation with pituitary hormone release. Endocrinology 119:1703-1707

Manna V (1991): Disurbi affecttivi bipolari e ruolo del calcio intraneuronale: Effetti terapeutici del trattamento con sali di litio e/o calcio antagonista in pazienti con rapida inversione di polarita. Minnerva Med 82:757-763

Marin J (1988): Vascular effects of calcium antagonists: Uses in some cerebrovascular disorders. Gen Pharmacol 19:295-306

Marksteiner J, Sperk G (1988): Concomitant increase of somatostatin, neuropeptide $Y$ and glutamate decarboxylase in the frontal cortex of rats with decreased seizure threshold. Neuroscience 26:379-385

Martinez-Vila E, Guillien F, Villanueva JA, Matiias-Guiu J, Bigorra J, Gil P, Carbonell A, Martinez-Lage JM (1990): Placebo-controlled trial of nimodipine in the treatment of acute ischemic cerebral infarction. Stroke 21:1023-1028

McDermut W, Pazzaglia P, Huggins T, Mikalauskas K, Leverich G, Ketter TA, Bartko J, Post RM (1995): Use of single case analysis in off-on-off-on trials in affective illness: A demonstration of the efficacy of nimodipine. Depression, in press

Mee E, Dorrnace D, Lowe D, Neil-Dwyer G (1988): Controlled study of nimodipine in aneurysm patients treated early after subarachnoid hemmorhage. Neurosurgery 22: 484-491
Meyer FB, Tally PW, Anderson RT, Sundt TM, Yaksh TL, Sharbrough FW (1986): Inhibition of electrically induced seizures by dihydropyridine calcium channel blocker. Brain Res 384:180-183

Meyer FB, Anderson RE, Sundt TM, Yaksh TL, Sharbrough FW (1987): Suppression of pentylenetetrazole seizures by oral administration of a dihydropyridine $\mathrm{Da} 2+$ antagonist. Epilepsia 28:409-414

Molchan SE, Lawlor BA, Hill JL, Martinez RA, Davis CL, Mellow AA, Rubinow DR, Sunderland T (1991): CSF monoamine metabolites and somatostatin in Alzheimer's disease and major depression. Biol Psychiatry 29:1110-1118

Montenegro R, Cornide E, Castro NM (1985): Nimodipine in the treatment of involutional depressive syndrome. In Proc First Int Nimotop Sympos, pp 345-358

Montgomery SA, Montgomery D, Baldwin D, Green M (1990): The duration, nature and recurrence rate of brief depression. Prog Neuro-Psychopharmacol \& Biol Psychiatry 14:729-735

Nadi NS (1988): The time course of chemical changes in the kindled rat brain. Soc Neurosci 14:1031 (abstract)

Olenik C, Meyer DK, Marksteiner J, Sperk G (1989): Concentrations of mRNA's encoding for preprosomatostatin and preprocholecystokinin are increased after kainic acid-induced seizures. Synapse 4:223-228

Olpe H, Balcar V, Bittinger H, Rink H, Sieber P (1980): Central actions of somatostatin. Eur J Pharmacol 63:127-133

Paczynsky RP, Meyer FB, Anderson RE (1990): Effects of the dihydropyridine $\mathrm{Ca} 2+$ channel antagonist nimodipine on kainic acid-induced limbic seizures. Epilepsy Res $6: 33-38$

Patel YC (1992): General aspects of the biology and function of somatostatin. In Weil C et al. (eds), Basic and Clinical Aspects of Neuroscience, Vol 4. Berlin, Springer-Verlag, pp 1-16

Patel YC, Reichlin S (1979): In Jaffe BM, Beheman HR (eds), Somatostatin, in Methods of Hormone Radioimmunoassay, 2nd ed. Weil C et al. (eds), Orlando, FL, Academic Press

Patel YC, Rao K, Reichlin S (1977): Somatostatin in human cerebrospinal fluid. N Engl J Med 296:529-533

Pazzaglia PJ, Post RM, Ketter TA, George MS, Marangell LB (1993): Preliminary controlled trial of nimodipine in ultrarapid cycling affective dysregulation. Psychiatry Res 49:257-272

Perlin JB, Lothman EW, Geary WA (1987): Somatostatin augments the spread of limbic seizures from the hippocampus. Ann Neurol 21:475-480

Peroutka SJ (1983): The pharamacology of calcium channel antagonists: A novel class of antimigraine agents? Headache $23: 278-283$

Phillis J, Kirkpatric KJ (1980): The actions of motilin, LH-RH, CCK-8, somatostatin, VIP, and other peptides on rat cerebral cortical neurons. Can J Physiol Pharmacol 58: 612-623

Physician's Desk Reference 44, Montvale, NJ, Medical Economics Company Inc. (1990), 1

Pickard JD, Murray GD, Illingworth R, Shaw MDM, Teasdale GM, Foy PM, Humphrey PRD, Lang DA, Nelson 
R, Richards P, Sinar J, Bailey S, Skene A (1989): Effect of oral nimodipine on cerebral infarction and outcome after subarachnoid hemorrhage: British aneurysm nimodipine trial. Br Med J 298:636-642

Pitkanen A, Jolkkonen J, Honkanen K-L, Riekkinen P (1987): The effect of pentylenetetrazol-induced convulsions on somatostatin-like immunoreactivity in rat cerebrospinal fluid. Neuropeptides 9:19-24

Pitkanen A, Beal MF, Reikkinen PJ (1988): Levels of somatostatin and neuropeptide $Y$ in pentylenetetrazol-kindled rat brain. Epilepsia 29:659

Post RM, Rubinow DR, King MA, Berrettini W, Gold PW (1988): Neuroactive substances in cerebrospinal fluid: Normal and pathological regulatory mechanisms. Ann. NY Sci 531:15-28

Randic M, Miletic V (1978): Depressant actions of metenkephalin and somatostatin in cat dorsal horn neurons activated by noxious stimuli. Brain Res 152:196-202

Renaud L, Martin J, Brazeau P (1975): Depressant actions of TRH, LH-RH, and somatostatin on the activity of central neurons. Nature 255:233-235

Rothman S (1984): Synaptic release of excitatory amino acid neurotransmitter mediates anoxic neuronal death. J Neurosci 4:1884-1891

Rubinow DR (1986): Cerebrospinal fluid somatostatin and psychiatric illness. Bio Psychiatry 21:341-365

Rubinow DR, Davis CL, Post RM (1995): Somatostatin in the central nervous system. In Bloom FE and Kupfer DJ (eds), Psychopharmacology: The Fourth Generation of Progress. New York, Raven Press, pp 553-562

Rubinow DR, Gold PW, Post RM, Ballenger JC, Reichlin S (1983): Cerebrospinal fluid somatostatin in primary affective disorder. Psychopharmacol Bull 19:422-425

Rubinow DR, Davis CL, Post RM (1992): Somatostatin in neuropsychiatric disorders. In Weill $C$ et al (eds), Basic and Clinical Aspects of Neuroscience, Vol 4. Berlin, SpringerVerlag, pp 29-32

Scharfman HE, Schwartzkroin PA (1988): Further studies of the effects of somatostatin and related peptides in CA1 of rabbit hippocampus. Cell Mol Neurobiol 8:411-429

Scharfman HE, Schwartzkroin PA (1989): Selective depression of GABA-mediated IPSP's by somatostatin in area CA1 of rabbit hippocampal slices. Brain Res 493:205-211

Serby M, Richardson SB, Twente S, Siekierski J, Corwin J, Rotrosen J (1984): CSF somatostatin in Alzheimer's disease. Neurobiol Aging 5:187-189

Shinoda H, Schwartz JP, Nadi NS (1989): Amygdaloid kindling of rats increases preprosomatostatin mRNA and somatostatin without affecting glutamic acid decarboxylase (GAD) mRNA or GAD. Mol Brain Res 5:243-246

Shinoda H, Nadi NS, Schwartz JP (1991): Alterations in somatostatin and proenkephalin mRNA in response to a single amygdaloid stimulation versus kindling. Mol Brain Res 11:221-226

Soininen HS, Jolkkonen JT, Reinikainen JK, Halonen TO, Riekkinen PJ (1984): Reduced cholinesterase activity and somatostatin-like immunoreactivity in cerebrospinal fluid of patients with dementia of the Alzheimer type. J Neurol Sci $63: 167-172$
Soininen HS, Riekkinen PJ, Partanen J, Helkata EL, Laulumaa V, Jolkkonen J, Reinikainen K (1988): Cerebrospinal fluid somatostatin correlates with spectral EEG variables and with parietotemporal cognitive dysfunction in Alzheimer patients. Neurosci Lett 85:131-136

Solomon GD (1985): Comparative efficacy of calcium antagonist drugs in the prophylaxis of migraine. Headache 25:368-371

Sorenson KV, Christensen SE, Dupont E, Hansen AP, Pedersen E, Orskov H (1980): Low somatostatin content in cerebrospinal fluid in multiple sclerosis. Acta Neurol Scand 61:186-191

Sorensen KV, Alslev T, Christensen SE (1987): CSF somatostatin in multiple sclerosis: Reversible loss of diurnal oscillation in relapses. Neurology 37:1050-1053

Sperk G, Marksteiner J, Gruber B, Bellmann R, Mahata M Ortler M (1992): Functional changes in neuropeptide $Y$ and somatostatin-containing neurons induced by limbic seizures in the rat. Neuroscience 50:831-846

Steardo L, Barone P, Hunnicutt E (1986): Carbamazepine lowering effect on CSF somatostatin-like immunoreactivity in temporal lobe epileptics. Acta Neurol Scand 74:140-144

Su T, Hauser P, Rubinow DR, Elpern S, Maloni HW, Krebs HM, Devinsky O, Post RM, McFarland HF (1990): CSF somatostatin (SRIF), mood, and cognition in multiple sclerosis. In Proc. 21st Congr Soc Psychoneuroendocrinol, Buffalo, NY (abstract)

Sunderland T, Rubinow DR, Tariot $P$, Cohen RM, Newhouse PA, Mellow MA, Mueller EA, Murphy DL (1987): CSF somatostatin in dementia, elderly depression and agematched controls. Am J Psychiatry 144:1313-1316

Tartara A, Maurelli M, Savoldi F (1984): Synchronizing, sedative, and anticonvulsive effects of centrally administered somatostatin in the conscious rabbit. Regul Pept 9:77-86

Todisco A, Campbell V, Dickinson CJ, DelValle J, Yamada $\mathrm{T}$ (1994): Molecular basis for somatostatin action: Inhibition of $\mathrm{c}$-fos expression and AP-1 binding. Am J Physiol 267:G245-G253

Tollefson GD (1990): Short-term effects of the calcium channel blocker nimodipine (Bay-e-9736) in the management of primary degenerative dementia. Biol Psychiatry 27:1133-1142

Ulrich G, Stieglitz RD (1988): Effect of nimodipine upon electroencephalographic vigilance in elderly persons with $\mathrm{mi}-$ nor impairment of brain functions. Drug Res 38:392-396

Vecsel L, Bollok I, Telegdy G (1983): Intracerebroventricular somatostatin attenuates electroconvulsive shock induced amnesia in rats. Peptides 4:293-295

Vecsel L, Kiraly C, Bollok I, Nacy A, Penke B, Telegdy G (1984): Comparative studies with somatostatin and cysteamine in different behavior tests on rats. Pharmacol Biochem Behav 21:833-837

Vezzani A, Wu HQ, Stasi P, Saminin R (1988): Effect of various calcium channel blockers on three different models of limbic seizures in rats. Neuropharmacology 27:451-458

Walsh TJ, Emrich DF, Winocus A, Banki C, Bissette G, Nemeroff CB (1985): Intrahippocampal injection of cysteamine depletes somatostatin and produces cognitive 
impairment in the rat. In Proc Soc Neuroscience 15th Annual Meeting 11:621 (abstract)

Wollheim CB, Winger BP, Ullrich S, Wuarin F, Schlegel W (1990): Somatostatin inhibition of hormone release: Effects on cytosolic $\mathrm{Ca}^{++}$and interference with distal secretory events. Metabolism 39:101-104
Wood PL, Etienne P, Lal S, Gauthier S, Cajal S, Nair NPV (1982): Reduced lumbar CSF somatostatin in Alzheimer's disease. Life Sci 31:2073-2079

Wurpel JND, Iyer SN (1994): Calcium channel blockers verapamil and nimodipine inhibit kindling in adult and immature rats. Epilepsia 2:443-449 